\title{
Awareness of Postpartum and Post Aborted Women Regarding Emergency Contraception
}

\author{
Fatma Ahmed Sabry ${ }^{1}$, Thorea Mohamed Mahmoud², Omima Mostafa Abd Elzaher³, \\ Safaa Ebrahim Ahmed ${ }^{4} \&$ Nadia Hussein Ahmed ${ }^{5}$ \\ ${ }^{1 .}$ Lecturer of Obstetric and Gynecological Nursing Department, Faculty of Nursing, Sohag University, Egypt. \\ 2. Assistant professor of Community Health Nursing Department, Faculty of Nursing, Sohag University, Egypt. \\ ${ }^{3 .}$ Lecturer of Community Health Nursing Department, Faculty of Nursing, Sohag University, Egypt. \\ 4. Assistant professor of Obstetric and Gynecological Department, Faculty of Nursing, Sohag University, Egypt. \\ 5. Assistant professor of Obstetric and Gynecological Department, Faculty of Nursing, Assuit University, Egypt.
}

\begin{abstract}
Background: Globally, there are 250 million pregnancies every year, one third of these is unintended pregnancy, one fifth of these undergo induced abortion and some of these undergo unsafe abortion. Unintended pregnancy has obvious association with health social and economic consequences. Aim: Assess knowledge, attitude and selfreported practice regarding emergency contraception among postpartum and post aborted women. Design: A descriptive research design was carried out in this study. Settings: The sample conducted at Family Planning Unit in Sohag University Hospital, Sohag General Hospital and Maternal- child health center (Dar Salama Abdallah). Sample: A purposive sample was carried out in this study. Subjects: was estimated to be 600 women. Tools: First: structured interview questionnaire, second: knowledge assessment sheet, third: attitude assessment sheet and fourth: self-reported practice assessment sheet. Results: This study revealed that near two third of women had poor knowledge about emergency contraception (EC), more than half of them had negative attitude toward it, the minority of them were used it before and the majority of them had unintended pregnancy previously. Conclusion: Poor knowledge and negative attitude regard EC is remain a major barrier regard wide spread EC use and had obvious role in occurrence unintended pregnancy. Recommendations: It is important to advise women toward using regular suitable contraception and keep EC for emergency purposes only as unprotected sexual intercourse to minimize unintended pregnancies and abortions.
\end{abstract}

\section{Keywords: Awareness, Emergency contraception, Postpartum, Post aborted \& Women.}

\section{Introduction}

Unprotected sexual intercourse or contraceptive method failure may lead to unintended pregnancies. Some women who had unintended pregnancies acquire abortion. Many of those are performed with unsafe condition and others have their pregnancies to full term causing increase the risk of morbidity and mortality. Unsafe abortion is a great public health problem in developing countries where women make several efforts to terminate unintended pregnancy before referred to health care and converting major cause of maternal mortality and morbidity. To avoid it, emergency contraceptive methods (EC) should using (WHO, 2019)

Unintended pregnancies are associated with adverse health outcomes. The woman has unintended pregnancy is more likely to slowness requesting antenatal care or has inadequate care that can affect the health for both the mother and her babies. Also, babies born as the result of unintended pregnancy become at a higher risk of diseases than other due to they are born with a low birth weight, be breastfed for fewer months, and high risk for developmental problems (British Medical Association, 2019)
EC is considered a type of recent contraception, which is recommended after unprotected sexual intercourse, which subordinate sexual abuse, wrong use of regular contraception or not using of contraception and failure of contraceptive method. EC plays necessary role in minimizing unintended pregnancy, unsafe abortion and decrease possibility of maternal morbidity and mortality that are great problems of maternal health. There are two types of EC- oral pills such as combined oral contraceptive pills (COCs), a progestin only pills (POPs), and intrauterine devices (IUDs) are currently used (International Consortium for Emergency Contraception, 2019 ).

EC is a safe method that accompanied with few side effects such as nausea and vomiting according to pills and infection in case of IUDs if not used properly. Effectiveness of EC is $75 \%$ regarding combined oral contraceptive pills, $85 \%$ regarding progestin only pills. According mechanism of action of emergency contraception it works through preventing tubal transportation of sperm and ovum, failure of fertilization and implantation. 
According IUDs, the protective effect is available when it is inserted within 5 days of unprotected sexual intercourse (O'Haeger et al., 2018)

Authentic methods of ECP include administration of two doses of a combination of estrogen and progestin pill. with estimated efficacies of $75 \%$. But it is not recommended due to nausea and other side effects. Currently, two $0.75 \mathrm{mg}$ doses of levonorgestrel are licensed for use within 72 hours of unprotected sex and another $0.75-\mathrm{mg}$ dose 12 hours after later. However, subsequent studies shows, which a single dose of $1.5 \mathrm{mg}$ is considered effective and enough, recently considered the evidence-based standard, and it may be effective up to 120 hours after unprotected sexual intercourse. In addition, this dose is easier for women and promote adherence. Recent results have proved that $10 \mathrm{mg}$ mifepristone at the time of presentation had to 120 hours after intercourse added good results (Shen et al., 2017)

The great factor minimizing the use of EC may be lack of information about their effectiveness and availability or unfavorable opinions about their safety due to poor information. Although the fact that a lot of modern contraceptives available worldwide, the problem of unintended pregnancy still exist which could be because gap of awareness, negative attitudes regards contraception or low accessibility (European medicines agency, 2019).

Health professionals nurses should explain future and ongoing contraception. Women must be informed that oral emergency contraception methods do not improve contraceptive cover for subsequent unplanned sexual intercourse and which women will need to have contraception or protect from sex to avoid the risk of unintended pregnancy. health professional nurse can 'quick start' combined hormonal contraception, the progestogen only pill (POP) or implant, introducing the woman has been proper informed and encouraged to have a pregnancy test in $\geq 3$ weeks. The injectable must be started immediately only when other methods are not efficient or acceptable and the woman has been appropriately informed and encouraged to have a pregnancy test in $\geq$ three weeks. Following administration of LNG, women continuing to use a hormonal method of contraception must be encouraged to have additional contraceptive precautions for seven days. Following administration of UPA, women continuing to have a hormonal method of contraception should be encouraged to have additional contraceptive precautions for 14 days (Singh, 2018).

\section{Significance of the study}

From clinical experience, there was a high incidence of unintended pregnancy and its poor consequences like unsafe abortion, maternal morbidity and mortality resulting from poor knowledge about family planning methods including emergency contraception. Considering the importance of EC in avoiding unintended pregnancy and unsafe abortion. Despite the emergency contraception has been available and registered for a long period in Egypt and some other Middle Eastern countries, it is remain relatively unknown and is examined controversially in such countries, the problem of unintended pregnancy still exists (Edelman, et al., 2018). Looking unsafe abortion as preventable cause of maternal mortality and morbidity, the WHO has recommended interventions like modern contraceptive services including emergency contraception (EC) as a way to mitigate unsafe abortions and reduce maternal morbidity and mortality (Bridge, 2019). Unsafe abortion has more adverse outcomes for women's health, millions of women end up with many problems like infection and hemorrhage, this may be immensely minimized by having EC.

Aim of the study:

Assess knowledge, attitude and self-reported practice regarding emergency contraception among postpartum and post aborted women.

Research questions:

- Did postpartum and post aborted women have a knowledge about emergency contraception?

- Did postpartum and post aborted women have a positive attitude towards emergency contraception?

- Have postpartum and post aborted women used any types of emergency contraception before?

\section{Subjects and Method \\ Research design:}

A descriptive research design was used to achieve the aim of the study.

Research setting and participants:

The study was conducted at the Family Planning Unit in Sohag University Hospital, Sohag General Hospital and (MCH) Maternal and child health center (Dar Salama Abdallah). These places had higher women's attendance rate from rural and urban regions in Sohag city and provide free services to women who are resident in Sohag city.

Subjects:

Sample type:

A purposive sample of postpartum and post aborted women were choosen in the study

Sample size:

600 women of postpartum and post aborted women carried out in this study.

\section{Sample size calculation:}

Sample size was calculated based on considering level of significance of $5 \%$, study power of $80 \%$, and 
by using the following formula: $\mathrm{n}=[2(\mathrm{Z} \alpha / 2+\mathrm{Z} \beta) 2$ $\times p(1-p)] /(p 1-p 2) 2$, Type of test $=$ two-sided where $\mathrm{n}=$ sample size required, $\mathrm{p}=$ pooled proportion of event, $\mathrm{p} 1-\mathrm{p} 2$ = difference in proportion of event, $\mathrm{Z}$ $\alpha / 2$ : This depends on level of significance, for $5 \%$ this is $1.96, \mathrm{Z} \beta$ : This depends on power, for $80 \%$ this is $0.84, \mathrm{n}=[2(1.96+0.84) 2 \times 0.55(1-0.55)] /(0.2) 2$ $=97$. Based on the previously mentioned formula, 600 women were recruited, (0.5) was used as the significance, 0.001 was used as the high significance.

\section{Inclusion criteria:}

Postpartum and post aborted women from (18-40) years, who agree to participate in the study and women had a previous unintended pregnancy.

\section{Exclusion criteria.}

Postpartum and post aborted women with any chronic or acute diseases as cardiac disease, restrictive lung disease, diabetes mellitus.

Tools of data collection:

Tool I: Structured interviewing questionnaire:

which included 4 parts:

Part I: Personal characteristics (This included age, age at marriage, residence, level of education, and occupation).

Part II: Menstrual history (This included age of menarche, duration of menstrual blood flow, amount of menstruation, menstrual regularity).

Part III: Obstetrical history (This included number of gravidity, Parity, unintended pregnancy, abortion and type of abortion).

Part IV: Family planning history (This included last contraceptive method, use length of use and causes of termination).

\section{Tool II: Knowledge assessment sheet:}

Questions to assess the women's level of knowledge about emergency contraception.. It was included 20 questions such as (hearing about emergency contraception, source of information, permission of EC in Egypt, availability of EC methods in Egypt, discuss EC methods with health care provider, types of emergency contraception, mechanism of action, doses are indicated, interval between the doses, side effects of contraindications, recommended time for using IUD as an emergency contraception?

A scoring system: a correct answer was scored 1, the incomplete 0.5 and incorrect answer 0 . The scores of the items were summed-up and the total divided by the number of the items, giving a mean score for the part. These scores were converted into a percent score, and means and standard deviations were computed. Women's total level of knowledge has been classified as follows,

- Women had poor knowledge $<50 \%$ of total knowledge score (1-9.5)

- Women had moderate knowledge $50 \%$ - $75 \%$ of total knowledge score (10-15)
- Women had good knowledge $>75 \%$ of total knowledge score (15.5-20)

Tool III: Attitude assessment sheet:

Questions to evaluate women's attitude toward EC. The woman attitudes were measured using 14 items such as (emergency contraception is important in the case of unprotected sexual intercourse, safely, effective, harmful to the body, cause sexually transmitted diseases, provide promiscuity, easily accessible, cheap, available to only the victims of rape, available without medical advice, available to women over 18 years of age, influence pregnancy in the future, encourage other women to use emergency contraception (Prof. Ali Ahmed Hussein Mostafa and prof. Emad Ahmed Hassan).

A scoring system: rated on a three point like scale as agree scored 1 , disagree scored 0 .

- Negative attitude $<50 \%$ of total attitude score (14 degree)

- Positive attitude while $\geq 50$ of total attitude score (5-10 degree)

Tool IV: Self-reported practice assessment sheet: Questions to assess Self-reported practice regarding emergency Contraception. It was included 6 questions:

A scoring system: For the practice items. The scores of the items were summed-up and the total divided by the number of the items, giving a mean score for the part. These scores were converted into a percent score, and means and standard deviations were computed.

Satisfactory practice if the

$\left\{\begin{array}{l}\text { percent score was } 60 \% \text {. } \\ \text { - Unsatisfactory less than } 60 \% \text {. }\end{array}\right\}$ Self-reported practice

\section{Validity of the tools:}

The content validity was tested for clarity, comprehensiveness, appropriateness, and relevance and reviewed by five experts in the obstetrics and gynecology nursing field and the community healthnursing field. Modifications were done according to the panel judgment to ensure clarity of sentences and appropriateness of the content.

\section{Reliability of the tools:}

The reliability of the tools was assessed through Cronbach's alpha test $\alpha=0$. 89. The tools' reliability was estimated through using the Pearson correlation coefficient test to compare variables. The Pearson correlation coefficient for the variables ranged between $(\mathrm{P} .<0.5)$ and $(\mathrm{P} .<0.001)$, which indicated a highly significant positive correlation between variables of the subjects.

\section{Ethical considerations:}

Before starting the research, ethical approval was obtained from the scientific research ethical committees of the faculties of nursing, Sohag University, Sohag General Hospitals and Maternal 
and child health center ( Dar Salama Abdallah). The researchers met both medical and nursing directors of the selected settings to clarify the purpose of the study and take their approval. Written consent was obtained from the postpartum, post aborted women to participate in the study after the objective of the study was explained to them. The researchers informed the postpartum, post aborted women that, the study was voluntary, they were allowed to not participate and they had the right to withdraw from the study at any time, without giving any reason. Moreover, they were assured that their information would be confidential.

\section{Pilot study}

It was carried out $10 \%$ (60) of postnatal and post aborted women to evaluate the validity, reliability and applicability of the tool, these women was excluded from the study sample, According to the results of the pilot, tools modifications was done therefore, the rewording or rephrasing of statements was done, also, any modification in the protocol. It also helped in the estimation of the time needed to fill the form

\section{Preparatory phase:}

It was based on the assessment data was obtained during the interviewing questionnaires, literature review, through learning, practices toward knowledge, attitude and practice toward emergency contraception

\section{Assessment phase:}

Data were collected from the beginning of October 2020 to the end of March 2021, in Obstetric and Gynecology at the Family Planning Unit in Outpatient Clinic in Sohag University Hospital, Sohag General Hospital and (MCH) Maternal and child health center (Dar Salama Abdallah), through three days per week. The researcher was attended to the hospital at 9:00 am to 1:00 pm. The researcher introduced her-self to the postpartum and post aborted women. Clear and simple explanations about the aim and nature of the study were discussed by the researcher with women. The interview took approximately 35-45 minutes for each woman to answer and fill the questionnaire to assess the knowledge, attitude and practice of postpartum, post aborted women regarding emergency contraception.

\section{Administrative design:}

An official permission letter was issued by the Dean of the Faculty of Nursing to the directories of Obstetrics and Gynecology department of Sohag University Hospital, Sohag General Hospital and $(\mathrm{MCH})$ Maternal and child health center (Dar Salama Abdallah).

\section{Statistical analysis:}

Statistical Package for Social Sciences (SPSS) version 21 was used for statistical analysis of the obtained data. Data presented using descriptive measures in the form of a number, percentage, mean and standard deviation. Chi-square test used for the differences between variables pre and posteducational program. Pearson correlation test was used to the association between variables. The Cronbach's alpha was used to assess the reliability of the second, third tool. 


\section{Results:}

Table (1): Distribution of the women according to their personal characteristics $(n=600$

\begin{tabular}{|c|c|c|}
\hline Socio- demographic characteristics & $(\mathrm{N}=600)$ & $\%$ \\
\hline $\begin{array}{l}\text { 1. Age } \\
\text { - Less than } 20 \text { years } \\
\text { - } 20-25 \text { years } \\
\text { - } 26-30 \\
\text { - } 31-35 \\
\text { - More than } 35\end{array}$ & $\begin{array}{c}95 \\
133 \\
157 \\
96 \\
119\end{array}$ & $\begin{array}{l}15.8 \% \\
22.0 \% \\
26.2 \% \\
16.0 \% \\
20.0 \%\end{array}$ \\
\hline Mean age \pm SD & & $28.00 \pm 5.84$ \\
\hline $\begin{aligned} \text { 2. Age at marriage } \\
\text { - } 15-<20 \\
\text { - } 20-<25 \\
\text { - }>25\end{aligned}$ & $\begin{array}{c}300 \\
241 \\
59\end{array}$ & $\begin{array}{l}50 \% \\
40 \% \\
10 \%\end{array}$ \\
\hline Mean age \pm SD & & $17.50 \pm 2.82$ \\
\hline $\begin{array}{l}\text { 3. Residence } \\
\text { - Urban } \\
\text { - Rural } \\
\end{array}$ & $\begin{array}{l}247 \\
353 \\
\end{array}$ & $\begin{array}{l}41.3 \% \\
58.7 \% \\
\end{array}$ \\
\hline $\begin{array}{l}\text { 4. Mother's educational level } \\
\text { - Illiterate } \\
\text { - Read and write } \\
\text { - Secondary } \\
\text { - University or higher } \\
\end{array}$ & $\begin{array}{c}78 \\
126 \\
228 \\
168 \\
\end{array}$ & $\begin{array}{l}13 \% \\
21 \% \\
38 \% \\
28 \% \\
\end{array}$ \\
\hline $\begin{array}{l}\text { 5. Mother's occupation } \\
\text { - House wife } \\
\text { - Employed } \\
\end{array}$ & $\begin{array}{l}346 \\
254 \\
\end{array}$ & $\begin{array}{l}57.8 \% \\
42.2 \%\end{array}$ \\
\hline
\end{tabular}

Table (2): Distribution of the women according history about emergency contraception ( $n=600)$

\begin{tabular}{|l|c|c|}
\hline Hearing about emergency contraception methods before & $(\mathbf{N = 6 0 0})$ & \% \\
\hline Ever heard about emergency contraception $(\mathbf{n = 6 0 0})$ & 456 & $76 \%$ \\
- Yes & 144 & $24 \%$ \\
\hline
\end{tabular}

Table (3): Distribution of the women according to their level of knowledge about emergency contraception methods $(n=456)$

\begin{tabular}{|c|c|c|c|c|}
\hline $\begin{array}{c}\text { Level of knowledge about emergency } \\
\text { contraception methods }\end{array}$ & $\begin{array}{c}\text { No } \\
(456)\end{array}$ & $\begin{array}{c}\% \\
(\mathbf{1 0 0})\end{array}$ & $\mathbf{X}^{2}$ & P.value \\
\hline Poor level $(<50 \%)$ & 282 & $61.9 \%$ & \multirow{3}{*}{185.382} & \multirow{3}{*}{$<0.001 * *$} \\
\hline Moderate level (50-75\%) & 110 & $24.0 \%$ & & \\
\hline Good level (>75\%) & 64 & $14.1 \%$ & & \\
\hline
\end{tabular}

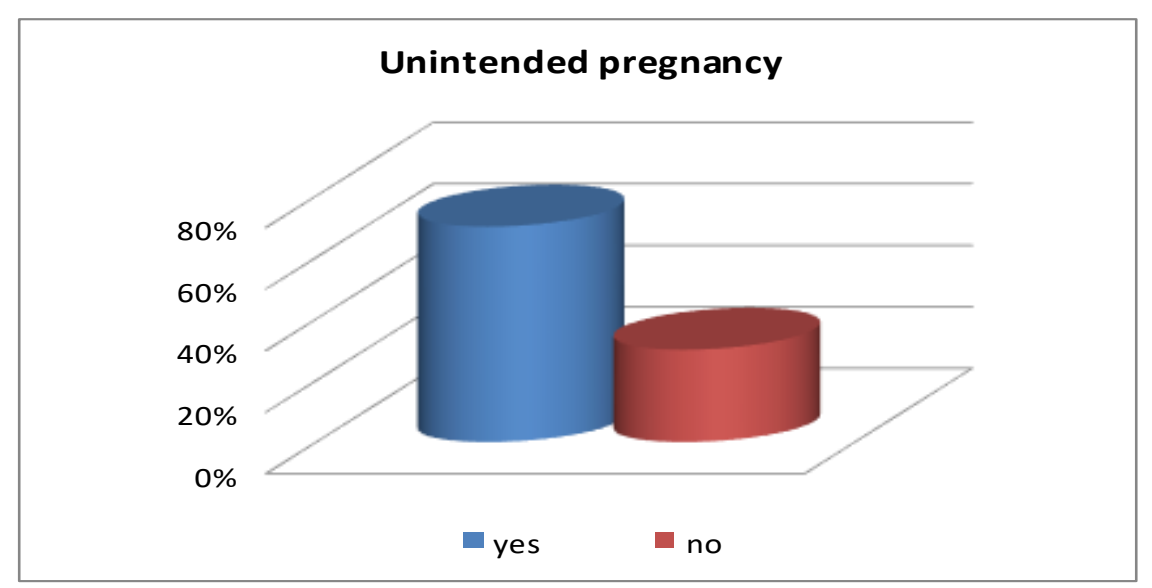

Figure (1) Distribution of the women according to the presence of unintended pregnancy in the past (n=456) 


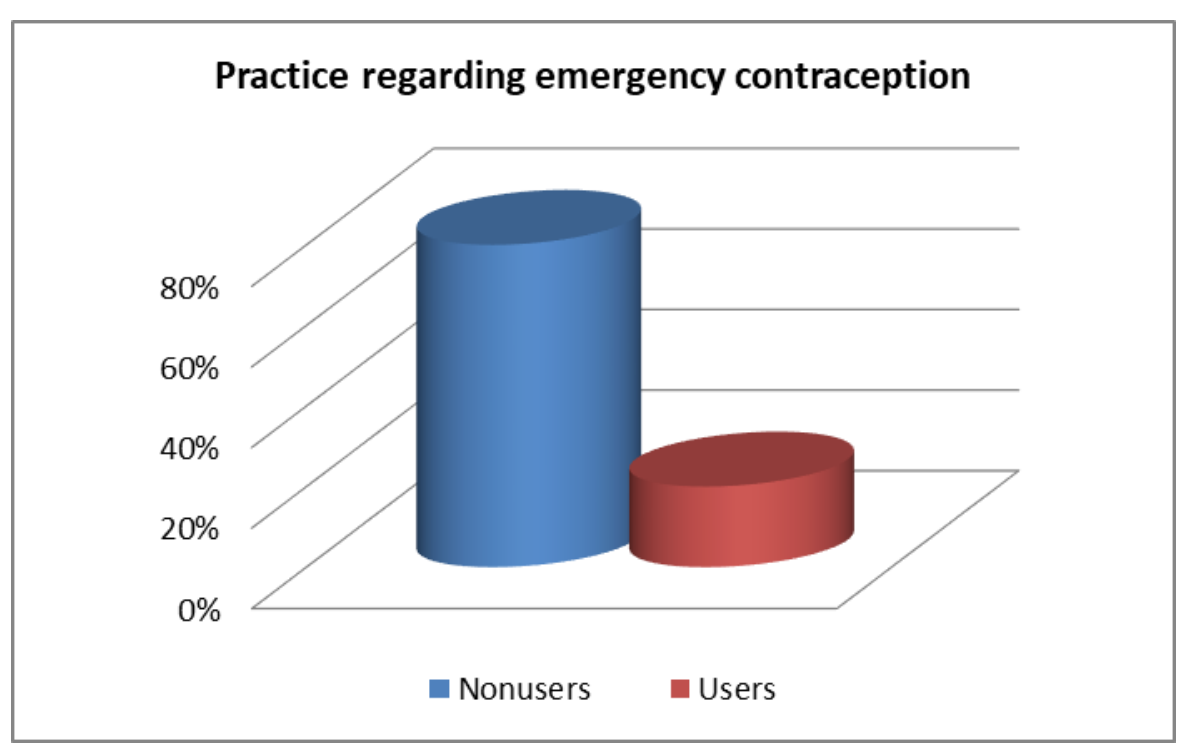

Figure (2) Distribution of the women according to their previous usage of emergency contraceptive method $(n=456)$

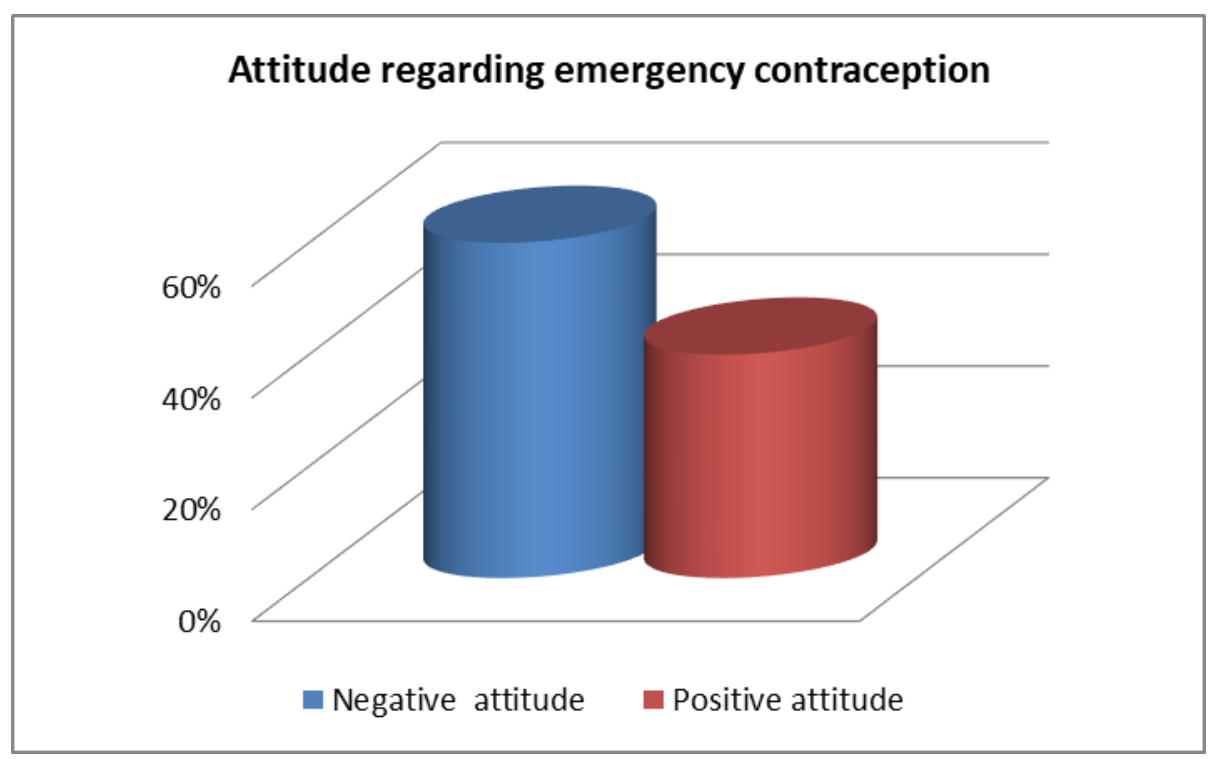

Figure(3) Distribution of the women according to their level of attitude toward emergency contraceptive methods $(n=456)$

Table (4): Relationship between the knowledge and attitude toward emergency contraceptive methods among the women $(n=456)$

\begin{tabular}{|c|c|c|c|c|c|c|c|c|}
\hline \multirow{3}{*}{ Knowledge } & \multirow{2}{*}{\multicolumn{2}{|c|}{ Total No }} & \multicolumn{4}{|c|}{ Attitude } & \multirow{3}{*}{$\mathbf{X}^{2}$} & \multirow{3}{*}{ P. Value } \\
\hline & & & \multicolumn{2}{|c|}{ Positive } & \multicolumn{2}{|c|}{ Negative } & & \\
\hline & $n=456$ & $\%$ & $n=244$ & $\%$ & $\mathrm{n}=\mathbf{2 1 2}$ & $\%$ & & \\
\hline$<50 \%$ "Poor" & 287 & 61.9 & 80 & 32.8 & 202 & 96.6 & & \\
\hline 50-75\%"Moderate & 105 & 24.0 & 101 & 41.4 & 9 & 2.9 & 204.633 & $<0.0011^{* *}$ \\
\hline$>75 \%$ "Good" & 64 & 14.1 & 63 & 25.8 & 1 & 0.5 & & \\
\hline
\end{tabular}


Table (5): Relationship between users and non-users attitude toward emergency contraceptive methods $(\mathrm{n}=\mathbf{4 5 6})$

\begin{tabular}{|c|c|c|c|c|c|c|c|c|}
\hline \multirow{3}{*}{ Practice } & \multirow{2}{*}{\multicolumn{2}{|c|}{ Total No }} & \multicolumn{4}{|c|}{ Attitude } & \multirow{3}{*}{$\mathbf{X}^{2}$} & \multirow{3}{*}{ P.Value } \\
\hline & & & \multicolumn{2}{|c|}{ Positive } & \multicolumn{2}{|c|}{ Negative } & & \\
\hline & $n=456$ & $\%$ & $n=244$ & $\%$ & $n=212$ & $\%$ & & \\
\hline Users & 88 & 19.3 & 86 & 35.2 & 2 & 0.9 & \multirow{2}{*}{90.168} & \multirow{2}{*}{$<0.001^{* *}$} \\
\hline Non users & 368 & 80.7 & 158 & 64.8 & 210 & 99.1 & & \\
\hline
\end{tabular}

Table (6): Relationship between the knowledge of emergency contraceptive methods among users compared to non-users $(n=456)$

\begin{tabular}{|c|c|c|c|c|c|c|c|c|c|c|}
\hline \multirow{3}{*}{ Practice } & \multirow{2}{*}{\multicolumn{2}{|c|}{ Total No }} & \multicolumn{6}{|c|}{ Level of knowledge } & \multirow{3}{*}{$\mathbf{X}^{2}$} & \multirow{3}{*}{$\begin{array}{c}\text { P. } \\
\text { Value }\end{array}$} \\
\hline & & & \multicolumn{2}{|c|}{ poor $(<50 \%)$} & \multicolumn{2}{|c|}{$(50-74 \%)$ moderate } & \multicolumn{2}{|c|}{$(\geq 75 \%)$ Good } & & \\
\hline & $n=456$ & $\%$ & $\mathrm{n}=\mathbf{2 8 7}$ & $\%$ & $\mathrm{n}=105$ & $\%$ & $n=64$ & $\%$ & & \\
\hline Users & 88 & 19.3 & 14 & 4.9 & 24 & 22.9 & 50 & 78.1 & \multirow{2}{*}{181.38} & \multirow{2}{*}{$<0.001^{* *}$} \\
\hline Non users & 368 & 80.7 & 273 & 95.1 & 81 & 77.1 & 14 & 21.9 & & \\
\hline
\end{tabular}

Table (1): Shows distribution of the women regarding to their personal characteristics. According age it was noticed that near of half $(48.2 \%)$ of the studied women their age between (20-30yrs) and the mean age \pm SD of the women was $(28.00 \pm 5.84$ years). Regarding residence, it was observed that more than half $(58.7 \%)$ of the women were living in rural areas. As regard mother's education level it is obvious that more than quarter of the studied women $(38.0 \%)$ had secondary level education. According mother's occupation it was observed that more than half $(57.8 \%)$ of the women was housewife.

Table (2): Reveals distribution of the women regarding to their history about emergency contraception, more than three quarter (76\%) of women who heard about emergency contraception before (456 women only from 600) and 24\% didn't hear about emergency contraception before

Table (3): Reveals distribution of the women regarding to their level of knowledge about emergency contraception methods, there were highly statistically significance different $(p<0.001)$ between the women according the levels of knowledge. More than half $(61.9 \%)$ of these women had poor level of knowledge about emergency contraception methods.

Figure (1): Shows distribution of the women according to the presence of unintended pregnancy in the past. There were highly statistically significance different $(\mathrm{p}<0.001)$ between women who had and women who hadn't pregnancy, more than two third $(70 \%)$ of women had unintended pregnancy.

Figure (2): Clears distribution of the women to their previous usage of emergency contraceptive method, the minority $(20 \%)$ of the women used emergency contraception methods before.

Figure(3): Shows distribution of the women according to their level of attitude toward emergency contraceptive methods. More than half $(60 \%)$ of the women had a negative attitude toward emergency contraceptive methods.

Table (4): Reveals the relationship between the knowledge and attitude of women regard emergency contraceptive methods. There were highly statistically significance different $(\mathrm{p}<0.001)$ between the women knowledge and their attitude regard emergency contraceptive methods, the majority $(96.6 \%)$ of the women who had poor knowledge also had negative attitude toward using emergency contraceptive.

Table (5): Illustrates the relationship between users and non-users women attitudes regard emergency contraceptive methods. There were highly statistically significance different $(\mathrm{p}<0.001)$ between the women attitude and practice, the majority $(99.1 \%)$ of the women who didn't use emergency contraception methods had a negative attitude toward it.

Table (6): Clears the relationship between the knowledge of women regarding emergency contraceptive methods among users compared to nonusers. There were highly statistically significance different $(\mathrm{p}<0.001)$ between the women knowledge and practice in which more than two third (78.1\%) of the women who used emergency contraception had a good knowledge regarding emergency contraceptive methods.

\section{Discussion}

World health organization considers emergency contraception as a safe, convenient and effective method of modern contraception, which will definitely help to reduce unintended pregnancies as well as its consequences like induced abortions, complications which may arise during or after unsafe abortions. (WHO, 2018)

This study revealed that the mean age and SD of the women was $(28.00 \pm 5.84)$ years, the mean age of marriage (17.50 \pm 2.82$)$ years and near half of the 
women were in the age group (20-30) years. This were come in accordance with (Rahman, et al., 2014) who performed with study in Bangladesh about "contraceptive practice among married women" and observed that the mean age of the women was $(29.00 \pm 6.5)$, the mean age of marriage $(17.18 \pm 2.7)$ and near than half of the women their age between (20-30) years. Also consistence with (Kose, et al., 2018) who performed with study in Nagpur, India about 'the knowledge of emergency contraception among married women of reproductive age" and noticed that the majority of the women their age group between (20-30) years.

According educational level in our study noticed more than quarter of the women had university education level but this was different with (El-Sabaa, et al, 2013) who performed with study in Alexandria, Egypt about "the awareness and use of emergency contraception among women of childbearing age" and observed that the women who had university education was more than half. The possible reason may be due to the lower socioeconomic status in Upper Egypt.

As regard occupation in this study observed near half of the women were employed this result was not consistence with (Kose, et al., 2018) who observed that the minority of the women were employed. According residence in our study more than third of the women were from urban areas this was different with (El-Sabaa, et al., 2013) who noticed that more than half of the women were from urban areas. The possible reason may be related to the nature of Upper Egypt most of its areas were rural.

According the occurrence of unintended pregnancy in the past the majority of the women had a previous unintended pregnancy before in our study. it was agree with (El-Sabaa, et al., 2013) who observed that the majority of the women had unintended pregnancy in the past.

The present study revealed that the majority of the women had a poor level of knowledge about emergency contraceptives and this agreed with (Nirmala Jaget, 2014) who performed with a study in India about "Assessment of knowledge and practice of contraceptives among women in reproductive age" and observed that the minority of the women aware about EC. Also agreed with (Gupta, 2017) who done a study in North India about 'Emergency contraception: knowledge, attitude and practices among recently married females in a rural area of North India' and noticed that the minority of the married women were aware of EC .

The levels of awareness regard EC among the women in the present study could be affected with their level of education, our study revealed that a highly statistically significance difference founded between the level of knowledge and the level of education $(\mathrm{P}<0.001)$ in which near than three quarters of women who had a good knowledge about emergency contraception had also university education. Also there was a statistically significance difference $(\mathrm{P}<0.05)$ between the level of knowledge and residence in which more than half of women lived in urban areas had a good knowledge about emergency contraception than women lived in rural areas. This finding agreed with (Chethana $\&$ Thejaswini, 2018) who done a study about Assessment of knowledge and attitude towards emergency contraception among postnatal mothers in Bruhat Bengaluru, they noticed education plays a key role in understanding and creating awareness towards emergency contraception among the studied women .

In this study noticed that the minority of the women used emergency contraception methods before. this result were consistence with (El-Sabaa, et al., 2013) observed that the minority of the women practiced emergency contraception before and also agreed with (Irfan, et al., 2019) \& (Worku, 2017) who performed with a study about the knowledge, attitude and practices of emergency contraception among drug dispensers working in Addis Ababa, Ethiopia.

The study showed that more than half of the women had a negative attitude toward it and this result was disagreed with (Asmare, et al., 2015) in which that more than half of the women had positive attitude toward emergency contraception.

The present study showed that a highly statistically significance different $(\mathrm{p}<0.001)$ between the women's knowledge and their attitude toward emergency contraceptive methods more than two third of the women who had good knowledge also had positive attitude toward emergency contraceptive, the majority of the women who had poor knowledge also had negative attitude toward using emergency contraceptive and this was consistence with (Eugene, et al., 2017) noticed that those with adequate knowledge generally showed a positive attitudes regards it $(p=0.000)$ also agreed with (Bugssa, et al., 2014) who performed with a study about 'factors associated with knowledge, attitude and practice towards emergency contraception among female clients" and stated that those who were knowledgeable had almost 3 times more likely positive attitude towards EC than their counterparts.

The present study revealed that there were highly statistically significance different $(p<0.001)$ between the women practice and attitude toward emergency contraceptive methods the most of the women who didn't used EC had a negative attitude toward it, also revealed that there were highly statistically significance difference $(\mathrm{P}<0.001)$ between practice and level of knowledge. In which the majority of the 
women who had a good knowledge were used EC and this is similar with (Kose, et al., 2018) \& (Bugssa, et al., 2014) it noticed that knowledge about EC was significantly associated with the usage of EC in the women. Those who had adequate knowledge about EC were five times more likely to use EC than their counterparts.

\section{Conclusion}

Based upon the results of the study, it can concluded that in spite of a greater percentage of women heard about emergency contraception but they had a poor level of knowledge about it, more than half of the studied women had a negative attitude regarding emergency contraception methods, the minority of the women used emergency contraception before. A large number of women who had unintended pregnancy previously had poor knowledge about emergency contraception.

\section{Recommendations}

From the previous findings the following

recommendations are suggested :

- It is important to counsel women regarding the use of suitable methods of regular contraception and keep emergency contraception in reserve for emergency purposes only as unprotected sexual intercourse to avoid unintended pregnancies and abortions with the help of media, health care providers and government health agencies.

- Educate and train all health care provider especially who work in family planning centers regard the emergency contraception to be able to provide the knowledge correctly and completely including existence of EC, availability, side effects associated with emergency contraceptives pills and how to deal with it and the timeframes involved in its use after unprotected sex.

- More researches should be done to evaluate the impact of family planning using on reducing the rate of unintended pregnancy.

\section{References}

- Asmare Tesfa, Asmamaw Demis Bizuneh, Temamen Tesfaye, Addis Adera Gebru, Yonas Yimam Ayene \& Birhan Alemnew Tamene (2015): Assessment of Knowledge, Attitude and Practice Towards Emergency Contraceptive Methods Among Female Students in Seto Semero High School, Jimma Town, South West Ethiopia. Science Journal of Public Health. Vol. 3, No. 4, pp. 478-486.

- British Medical Association (2019): The Law and ethics of abortion. 2019,https://www.bma.org.uk. [Accessed 30April 2019]
- Bridge IT, (2019): The effectiveness of bridging from emergency to regular contraception.https://www.isrctn.com/ISRCTN7061 6901[Accessed 22 July 2019].

- Bugssa G, Kahsay T, Asres A, Dimtsu B, \& Tsige Y, (2014): factors associated with knowledge, attitude and practice towards emergency contraception among female clients of Ethiopian Immigration and Nationality Affairs Office. J Community Med Health Educ 4: 305.

- Chethana R, \& Thejaswini P, (2018): Assessment of knowledge and attitude towards emergency contraception among postnatal mothers in Bruhat Bengaluru MahanagaraPalike referral hospital. International Journal of Community Medicine and Public Health. 2018 Sep; 5(9):3813.

- Edelman AB, Jensen JT, McCrimmon S, Messerle-Forbes M, O'Donnell A, \& Hennebold JD (2018). Combined oral contraceptiveinterference with the ability of ulipristal acetate to delay ovulation: a prospective cohort study. Contraception 2018

Dec;98(6):463e6.https://doi.org/10.1016/j.contracep tion.2018.08.003.

- El-Sabaa HA, Ibrahim AF, \& Hassan WA, (2013): Awareness and use of emergency contraception among women of childbearing age at the family health care centers in Alexandria, Egypt. J Taibah Univ Med Sci, 8:167-172.

- Eugene J Kongnyuy, Pius Ngassa, Nelson Fomulu, Charles Shey Wiysonge, Luc Kouam, \& Anderson S. (2017): A survey of knowledge, attitudes and practice of emergency contraception among university students in Cameroon. BMC Emergency Medicine; 7:7.

- European medicines agency. ellaone authorisation details (2019): .https://www.ema.europa.eu/en/medicines/human.

[Accessdate 22 July 2019]

- Gupta RK, Singh P, Gupta C, Kumari R, Langer B, \& Gupta R, (2017): Emergency contraception: knowledge, attitude and practices among recently married females in a rural area of North India. Int $\mathbf{J}$ Res Med Sci. 2017 Oct;5(10):4450

- International Consortium for Emergency Contraception. Status \& availability database (2019): https://www.cecinfo.org/country-bycountry-information/status-availability-database/. [Accessed 22 July 2019]

- Irfan F, Karim SI, Hashmi S, Ali S, \& Ali SA. (2019): Knowledge of emergency contraception among women of childbearing age at a teaching hospital of Karachi. J Pak Med Assoc; 59(4):23540.

http://ecommons.aku.edu/cgi/viewcontent.cgi?articl $\mathrm{e}=1004 \&$ context=pakistan_fhs_mc_fam_med. 
- Kose V, \& Sulbha, (2018): Knowledge of emergency contraception among married woman of reproductive age in rural based teaching hospital of Nagpur, Maharashtra, India. Journal of South Asian Federation of Obstetrics and Gynecology. May august;4(2):106 -109.

- NirmalaJaget L, NivedhanaArthi P, Jayavani R. L, ShallyMagon, \& PadmaAlaganandam. (2014): Assessment of knowledge and practice of contraceptives among women in reproductive age attending outpatient department at a sub-urban centre in Pondicherry, India Indian Journal of Basic and Applied Medical Research; December 2014: Vol.-4, Issue- 1, P. 196-209

- O'Haeger K, Lamme J, \& Cleland K(2018): State of emergency contraception in the U.S., Contracept Reprod Med 2018;3:20

- Rahman A, Rahman M, Huq S, \& Hossain S, (2014): Contraceptive Practice of Married Women: Experience from a Rural Community of Bangladesh AKMMC J 2014; 5(1): 14-18

- Shen J, Che Y, Showell E, Chen K, \& Cheng L (2017): Interventions for emergency contraceptionCochrane Database Syst Rev 2017;8:CD001324.

- Singh S, Remez L, Kwok L, \& Onda T (2018): Abortion worldwide: Uneven progress and unequal access. New York: Gutt-macher Institute; 2018

- Worku H, \& Teklu S. (2017): Knowledge, attitude and practices of emergency contraception among drug dispensers working in Addis Ababa. Ethiopia Med J; 49:7-15.

- WHO, (2018): Ensuring human rights in the provision of contraceptive information and services: Guidance and recommendations. Available:http://apps.who.int/iris/bitstream/.

- WHO model list of essential medicines. (2019): https://www.who.int/medicines/publications/essenti almedicines/en/. [Accessed 30 April 2019] 